\title{
EL RECURSO DE PROTECCIÓN ENTRE EXIGENCIAS DE URGENCIA Y SEGURIDAD JURÍDICA
}

\author{
Andrés Bordali Salamanca*
}

\begin{abstract}
RESUMEN
El trabajo analiza el contexto histórico y político chileno que explica la creación del Recurso de Protección. Ese contexto es el del gobierno de la Unidad Popular (1970-1973). Superada la crisis política que sirvió de justificación para la creación del Recurso de Protección, el autor propone reformular la tutela de urgencia de los derechos fundamentales, de modo de hacerla más eficaz, más respetuosa del derecho a un debido proceso de los justiciables y con mayores grados de seguridad jurídica. Para ello propone modificaciones normativas e interpretativas al sistema de tutela jurisdiccional de derechos fundamentales, articulando de mejor modo las vías procesales constitucionales con las civiles y las administrativas. Para unificar las decisiones de los tribunales en materia de derechos fundamentales, sugiere la creación de un procedimiento casatorio ante el Tribunal Constitucional.
\end{abstract}

RECURSO DE PROTECCIÓN - TUTELA DE URGENCIA - SEGURIDAD JURÍDICA

\section{"Recurso de Protección" between exigencies of urgency and legal certainty}

\begin{abstract}
This paper analyzes the Chilean historical and political context that explains the origins of the so called "Recurso de proteccion". That context was the Popular Unity government (19701973). Now, when that political crisis has been overcome, the author proposes a reformulation of the urgent protection of constitutional rights in order to make it more effective, more respectful of due process of law and more certain. He advocates changes to regulations and interpretations of the system of judicial protection of fundamental rights, by better articulating the constitutional proceedings with private and administrative ones. In order to unify the ratio decidendi of judicial decisions on constitutional rights, he suggests the creation of a cassation procedure before the Constitutional Court.
\end{abstract}

\section{RECURSO DE PROTECCIÓN - URGENT REMEDIES - LEGAL CERTAINTY}

* Abogado, Doctor en Derecho, Profesor de Derecho Procesal y Constitucional en la Facultad de Ciencias Jurídicas y Sociales de la Universidad Austral de Chile, Valdivia, Chile. Este trabajo fue realizado en el marco y con el financiamiento del proyecto Fondecyt n ${ }^{\circ} 1050388$ (2005-2006) sobre "Certeza e igualdad en la tutela jurisdiccional de los derechos fundamentales", del cual el autor de este trabajo es su investigador responsable.

Artículo recibido el 30 de septiembre de 2006 y aceptado para su publicación por el Comité Editorial el 6 de noviembre de 2006. 


\section{INTRODUCCIÓN}

$\mathrm{E}$ s curioso observar cómo ha cambiado la apreciación de la doctrina sobre el Recurso de Protección. De ser durante aproximadamente más de dos décadas una verdadera llave maestra del Estado de Derecho chileno, la única vía que permitía obtener una oportuna y efectiva tutela judicial para prácticamente toda posición jurídica subjetiva de los ciudadanos, hoy en día se lo cuestiona por varios motivos. Esas críticas son de dos tipos: sustanciales y procesales.

Entre las críticas sustanciales se puede mencionar aquella que sostiene que el Recurso de Protección ha sido una vía para la vulgarización de nuestro Derecho. Producto de la escasa densidad normativa que tienen los derechos fundamentales, ya que ni la Constitución ni la ley han colmado su contenido, han terminado los tribunales de justicia por configurarlos normativamente. Se ha procedido así a desformalizar nuestro Derecho construyendo una jurisprudencia en la materia basada en la pura equidad para el caso concreto. A todo ello se suma el problema de la "propietarización" de los derechos, que ha abierto el recurso prácticamente a todos los derechos fundamentales reconocidos en la Constitución y no a los que expresamente el constituyente consideró dentro de esta tutela privilegiada (art. 20 CPR). En otros casos la "propietarización" de los derechos ha permitido dar tutela urgente a posiciones jurídicas subjetivas que poco o nada tienen que ver con auténticos derechos fundamentales.

En otras oportunidades se dice que las decisiones judiciales de protección han impedido formar una dogmática constitucional consistente, afectando con ello la seguridad jurídica en materia de derechos fundamentales. Una tutela de urgencia y provisional de los derechos fundamentales se mostraría incapaz de contribuir a consolidar una dogmática constitucional en nuestro país.

Procesalmente, el Recurso de Protección ha significado alterar toda la organización jurisdiccional chilena. En primer lugar ha subvertido el principio fundamental en materia judicial que señala que el ciudadano debe poder recurrir en primera instancia al tribunal más cercano posible, idealmente ubicado próximo a su vecindario, pueblo o ciudad. Y si se trata de la tutela de derechos fundamentales, los bienes jurídicos más preciados por nuestra sociedad, con mayor razón ese ciudadano debe poder pedir tutela al tribunal que le es más cercano territorialmente. No aparece justificable haberle encomendado a una Corte de Apelaciones la competencia en primera instancia del Recurso de Protección. Estas Cortes se encuentran lejos del ciudadano común. En las grandes ciudades se encuentran situadas lejos de los barrios. Y en los pueblos y zonas rurales significará que el afectado o su abogado tengan que trasladarse a otra ciudad. Se dificulta y se encarece de este modo el acceso a la justicia.

Por otra parte, encomendarle a las Cortes de Apelaciones la competencia en primera instancia de estos procedimientos hace que las distraiga de su competencia natural cual es fallar dentro de un plazo razonable los recursos de apelación. La experiencia en nuestro país indica que las Cortes dedican mucho tiempo a las protecciones descuidando el conocimiento oportuno y adecuado de las apelaciones. 
Pero hay más. Tenemos a nuestra Corte Suprema fallando una enorme cantidad de apelaciones en materia de protección dejando de lado su tarea principal cual es fijar la correcta interpretación de la ley a través del Recurso de Casación en el Fondo. Y si tenemos una Corte de Casación que no conoce oportuna ni adecuadamente los recursos de casación, no está cumpliendo entonces adecuadamente con su cometido esencial.

Más todavía. Las Cortes de Apelaciones y la Corte Suprema han rivalizado en ocasiones con el Tribunal Constitucional en la interpretación configurativa de los derechos fundamentales, lo que claramente afecta la seguridad jurídica dentro de un Estado de Derecho.

A todo lo anterior podemos agregar que la regulación del Recurso de Protección mediante un Auto Acordado viola el principio de legalidad en materia procesal. Por otra parte, ese Auto Acordado niega el derecho fundamental a un debido proceso de los justiciables al desconocer el derecho de defensa de los recurridos.

¿Qué explica que hayamos creado un instrumento capaz de producir tantas alteraciones en nuestro sistema jurídico? La primera hipótesis que sostendré en este trabajo expresa que el Recurso de Protección fue creado como instrumento de lucha política. Se trata de una propuesta política que quería robustecer el papel de los tribunales superiores de justicia frente a los poderes democráticos "progresistas" (Legislativo y Administrativo) de un momento determinado de nuestra historia nacional.

Sostendré por otra parte dos hipótesis más. Ellas son en lo esencial jurídicas pero están claramente influenciadas por el problema político señalado en la primera hipótesis. La primera de estas hipótesis jurídicas señala que la alteración del orden jurídico con el Recurso de Protección se debió a que intentó sustituir tanto a la legislación procesal civil como a la procesal administrativa en materia de tutela jurisdiccional urgente de derechos. La segunda de estas hipótesis jurídicas dirá que con el Recurso de Protección no se pensó en un instrumento que contribuiría a conformar la dogmática constitucional de los derechos fundamentales asegurando a su vez el valor seguridad jurídica. Con él sólo se buscó urgencia de la respuesta jurisdiccional como alternativa a la autotutela. Todo ello, como veremos, se obtuvo pagando un enorme costo en términos del funcionamiento global del sistema jurídico chileno.

La maduración de nuestro Estado de Derecho debe llevar a encomendar a los tribunales ordinarios de base la tutela de los derechos fundamentales. El Tribunal Constitucional debe encargarse de unificar los criterios jurisprudenciales en materia de derechos fundamentales. El Recurso de Protección, tal como se encuentra regulado y funciona al día de hoy, ya no se justifica.

En las páginas que siguen intentaré justificar esas hipótesis. Me referiré primeramente (I) al contexto histórico y político del nacimiento del Recurso de Protección. Enseguida (II) analizaré cómo opera la tutela de urgencia en el proceso civil y en el proceso administrativo que fue lo que intentó asumir el Recurso de Protección. Luego (III) estudiaré si la tutela de urgencia es trasladable al campo del proceso constitucional de las libertades y cómo se compatibiliza con la seguridad jurídica. 


\section{CONTEXTO HISTÓRICO Y POLÍTICO DEL NACIMIENTO Del Recurso de Protección}

Los instrumentos jurídicos responden a necesidades políticas, morales, sociales y económicas de un momento determinado. El Recuso de Protección se inscribe en esa dinámica. ${ }^{1}$ Sin la experiencia del gobierno socialista de Salvador Allende lo más probable es que hasta el día de hoy no habríamos conocido nada similar a este procedimiento. El Recurso de Protección nace en el contexto de la vía chilena hacia el socialismo impulsada por el gobierno de la Unidad Popular entre 1970 y $1973 .^{2}$

Frente a un proceso político de socialización de los medios de producción, un grupo de parlamentarios de derecha ${ }^{3}$ comienza a discutir sobre la necesidad de poder frenar urgentemente ante los tribunales de justicia a la Administración del Estado. Y la verdad es que no se ideó para dar tutela a todos los derechos fundamentales de los ciudadanos, sino que se pensaba principalmente en tutelar urgentemente la propiedad. ${ }^{4}$ Tampoco se lo ideó contra toda persona que vulnerara ese derecho de propiedad sino sólo contra la Administración del Estado. ${ }^{5}$ Nace de este modo la Protección de la necesidad de contar con un contencioso-administrativo urgente para dar tutela a la propiedad. También se pensó que se podría utilizar para derechos sensibles políticamente como el derecho de reunión y de opinión que podían ser amagados por esa misma Administración. Con el tiempo se amplió su utilización siendo útil para resolver los conflictos no sólo entre los privados y la Administración del Estado sino entre los propios privados. Y desde luego

${ }^{1}$ Un sector de nuestra doctrina constitucional coincide en señalar que el Recurso de Protección nace de una determinada crisis política, como lo fue la del gobierno de la Unidad Popular. Vid. últimamente. Pfeffer, E. "La acción constitucional de protección y su regulación: situación actual y prospectiva", en Estudios Constitucionales, año $2 \mathrm{n}^{\circ} 1$, Universidad de Talca, 2004, p. 160.

${ }^{2}$ En el constitucionalismo chileno del siglo XIX también se hablaba de la protección de los derechos fundamentales, por lo que en rigor el amparo o protección de derechos fundamentales nace antes del conflicto político de 1970. Sin embargo, en cuanto al ámbito de los derechos fundamentales objeto de protección, tribunales competentes, tipo de procedimiento y efectos de la sentencia, el Recurso de Protección no tiene antecedentes directos en nuestro Derecho patrio. Para un análisis histórico de la protección de los derechos fundamentales en Chile remito al trabajo de Zúñiga, F. "Recurso de protección: algunas notas sobre sus antecedentes históricos en el siglo XIX”, en Gaceta Jurídica, ${ }^{\circ}$ 198, diciembre 1996, passim.

${ }^{3}$ Me refiero al proyecto de reforma constitucional de 1972 de los diputados Diez y Arnello, repuesto un año más tarde por los senadores Diez y Jarpa.

${ }^{4}$ Los empresarios, comerciantes y agricultores durante el período 1970-1973 tuvieron que luchar contra tres tipos de actividades de la Administración que afectaban sus propiedades: expropiaciones, intervenciones y requisiciones. Sobre el particular vid. Millar, J. “Alcance del control de legalidad. Su evolución a propósito de los actos administrativos requisitorios, durante 1970-1973”, en Revista de Derecho, Universidad Austral de Chile, Vol. XI, Diciembre 2000, pp. 82 a 94.

${ }^{5} \mathrm{Al}$ menos así figuraba en la primera propuesta elaborada por el Departamento de Derecho Público de la Universidad de Chile. En la propuesta posterior de los profesores Jaime Navarrete y Eduardo Soto Kloss el Recurso de Protección asume una perspectiva mucho más amplia, ya que se podía interponer no sólo contra la Administración del Estado, sino también contra particulares, Poder Judicial, Congreso Nacional, etcétera. En definitiva, contra "quienquiera" que fuese el que vulnerara un derecho fundamental, por lo que asume una dimensión más amplia que el de un contencioso-administrativo. 
el abanico de derechos fundamentales que podían obtener tutela por esta vía se amplió ostensiblemente.

Hasta antes de los años setenta del siglo pasado no había habido mucha necesidad de contar con un contencioso-administrativo para hacer frente al poder abusivo de la Administración del Estado. No sólo no se tenía un proceso administrativo de carácter urgente sino que ni siquiera existían vías contencioso-administrativas ordinarias, ya que, como sabemos, bajo la Constitución de 1925 jamás se crearon los tribunales de lo contencioso-administrativo como anunciaba el artículo 87 de esa Carta. Para algunos no existía simplemente la posibilidad de controlar a la Administración del Estado ante los tribunales de justicia. Para otros, a falta de los tribunales de lo contencioso-administrativo eran los tribunales ordinarios los llamados a dar esa tutela. ${ }^{6}$ Como sea, la experiencia política chilena parece indicar que hasta antes de 1970 la Administración del Estado no había comportado un verdadero peligro para los derechos de los ciudadanos, específicamente para la propiedad de los medios de producción.

Sin embargo, aun si pensamos que los jueces ordinarios eran competentes bajo la Carta de 1925 para conocer del contencioso-administrativo, la verdad es que el Código de Procedimiento Civil (en adelante CPC) no contenía ninguna vía procesal adecuada para hacer frente con cierta urgencia a una violación de derechos. Sólo estaban los interdictos posesorios o juicios sumarios que tutelaban exclusivamente el hecho de la posesión de bienes inmuebles. La alternativa habría sido utilizar el juicio ordinario y quizá intentar dentro de él una medida cautelar innominada que autoriza el artículo 298 CPC. Sin embargo, tanto en el pasado como hasta los días presentes esas medidas cautelares innominadas han tenido una bajísima utilización. Ha existido una reticencia tanto de los abogados como de los jueces en la utilización de medidas cautelares innominadas. ${ }^{7}$

Por otra parte, utilizar las vías ordinarias habría comportado solicitar la tutela a un juez de letras con posibilidad de apelar ante una Corte de Apelaciones y sólo vía casación llegar ante la Corte Suprema. Como sabemos, con la regulación que se le dio al Recurso de Protección se atribuyó esa competencia a los tribunales superiores de justicia. La explicación para encomendar en definitiva a esos tribunales el conocimiento del Recurso de Protección y no a los jueces de base era que se necesitaba de un tribunal de mayor categoría y conocimiento jurídico puesto que ese órgano contaría con unas facultades muy amplias para dar el amparo requerido. ${ }^{8}$ Un juez de letras significa un

${ }^{6}$ Vid. Soto Kloss, E. "Lo contencioso administrativo y los tribunales ordinarios de justicia”, en Revista de Derecho Público, Nos 21/22, 1977, pp. 233 a 249.

${ }^{7}$ Juan Carlos Marín atribuye la escasa utilización en Chile de las medidas cautelares innominadas a su prácticamente nula regulación legal, al escaso tratamiento doctrinal y a la falta total de una jurisprudencia configuradora de la institución. Cfr. Marín, J. C. Las medidas cautelares en el proceso civil chileno. Doctrina, jurisprudencia y Derecho comparado, Editorial Jurídica de Chile, Santiago, 2004, pp. 465 y 466.

${ }^{8}$ Así lo manifestó el Comisionado Ortúzar en la Comisión de Estudio de una Nueva Constitución. Vid. este punto en Soto Kloss, E. El Recurso de Protección. Orígenes, doctrina y jurisprudencia, Editorial Jurídica de Chile, Santiago, primera edición, 1982, p. 45. 
tribunal unipersonal y con poca experiencia en el ejercicio jurisdiccional por lo que no era adecuado para ejercer tan amplias facultades.

Más allá de ser absolutamente cuestionable esta explicación técnica sobre el sentido de alterar radicalmente el cuadro de competencias de nuestros tribunales de justicia, creo que hay una justificación política en esta decisión. En efecto, como se trataba de hacer frente a una Administración del Estado activa que intentaba profundizar en un proceso de socialización de los medios de producción a través de expropiaciones, intervenciones, requisiciones o tomas materiales de bienes, es plausible suponer que era más apropiado que fueran los tribunales superiores de justicia los encargados de controlar la actividad administrativa. Especialmente relevante era que la Corte Suprema controlara los actos de la Administración a través de un recurso ordinario como lo es la apelación y no a través de un recurso extraordinario y de derecho estricto como lo es el Recurso de Casación en el Fondo. Este último recurso le daba a la Corte Suprema poco margen de maniobra y la imposibilidad de conocer de cuestiones fácticas. La Corte Suprema debía tener la última palabra en la tutela de los derechos fundamentales pudiendo conocer además ampliamente de la cuestión debatida. En este sentido, era conveniente que figurara como tribunal de apelación (tribunal de hechos y de Derecho) y no de casación (tribunal de Derecho).

Era muy relevante encargar a la Corte Suprema la tutela de los derechos fundamentales vía apelación porque ésta se había manifestado en un par de ocasiones contrariando al gobierno socialista. ${ }^{9}$ Para la oposición política era importante contar con el apoyo de la Corte Suprema en la defensa de la propiedad de las empresas y otros derechos.

La crisis política desatada durante el gobierno de la Unidad Popular aceleró la prisa de contar con un contencioso-administrativo especial que con un carácter urgente podía dejar sin efecto un acto de la Administración del Estado que afectara un derecho, especialmente el de propiedad. El Golpe de Estado impidió que se pudiera concretar la idea. La propuesta volvió a aparecer en la Comisión de Estudio de una nueva Constitución y se lo reguló posteriormente, como sabemos, en el Acta Constitucional No 3 de 1976. Luego pasó al artículo 20 de la Constitución de 1980.

Como el Recurso de Protección era un instrumento de lucha dentro de un grave conflicto político fue concebido con una clara impronta elitista y autoritaria. Elitista en el sentido que arrancó la competencia del juez que debía ser naturalmente competente -el juez de letras- para dárselo a los tribunales superiores de justicia. Estos tribunales se encuentran territorialmente más alejados de las necesidades y el sentir del ciudadano común. ¿Cómo se justifica que un ciudadano de Punta Arenas tenga que apelar para ante un tribunal Santiago de una decisión de un tribunal de justicia que no ha dado tutela a sus derechos fundamentales? Eso se acerca bastante a la denegación de justicia.

\footnotetext{
${ }^{9}$ Véase a modo de ejemplo el Acuerdo de la Corte Suprema de fecha 12 de abril de 1973 bajo la presidencia de don Enrique Urrutia Manzano enviado al Presidente de la República. En ese acuerdo el pleno de la Corte Suprema representa duramente al Presidente de la República la actitud asumida por el Intendente de Santiago al no despachar la fuerza pública para desocupar una propiedad agro-industrial, como lo había ordenado un tribunal de justicia.
} 
Está claro que sólo pueden apelar y sustentar adecuadamente su defensa ante la Corte Suprema quienes tengan los medios económicos para hacerlo. Para el resto el acceso a la justicia sólo es un flatus vocis. ${ }^{10}$

Tiene una impronta autoritaria el Recurso de Protección porque el diálogo procesal fue desterrado casi absolutamente de él haciendo de las Cortes de Apelaciones un juez inquisidor con amplios poderes para llevar adelante el proceso y encontrar por sí toda la verdad.

Especial gravedad reviste el hecho que este tribunal elitista y autoritario ha desplazado a los jueces civiles de base en el conocimiento y fallo de las disputas entre particulares. Asimismo se ha constituido en el tribunal administrativo de base por antonomasia.

En definitiva, podemos concluir que el Recurso de Protección nació bajo unas determinadas coordenadas políticas hoy en día completamente diferentes. Si ello es así, ¿no será aconsejable normalizar nuestra tutela jurisdiccional de urgencia de los derechos fundamentales encomendando tal misión a los jueces civiles y a los jueces que controlan ordinariamente a la Administración del Estado? En el apartado siguiente analizaré cómo funciona la tutela de urgencia en materia procesal civil y procesal administrativa.

\section{LA TUTELA DE URGENCIA EN EL PROCESO CIVIL Y EN EL PROCESO ADMINISTRATIVO}

\section{Sobre las modalidades de la tutela de urgencia}

La tutela declarativa ordinaria supone articular un contradictorio en términos tales que las partes pueden ordenada y pausadamente realizar sus alegaciones e introducir los materiales probatorios a fin de intentar convencer al tribunal sobre la veracidad de sus afirmaciones. Los valores centrales de esta tutela son el respeto irrestricto del debido proceso de cada una de las partes así como permitir alcanzar al tribunal la convicción sobre la verdad de los hechos afirmados. En materia civil esa convicción se sostiene normalmente bajo un criterio de probabilidad prevaleciente que es un standard de convicción menos elevado que el que se exige en algunos sistemas procesales penales como lo es el de la convicción más allá de toda duda razonable. ${ }^{11}$ Este último criterio rige en nuestro Código Procesal Penal (art. 340). Todo ello supondrá desarrollar un iter procesal pausado. La reconstrucción de los hechos a los cuales el juez aplicará la ley no es cuestión fácil ni puede realizarse con prisas.

${ }^{10}$ Se podrá decir que en los países que tienen un amparo de derechos fundamentales ante el Tribunal Constitucional (Alemania, España, etc.) sucede lo mismo que en Chile. Sin embargo hay una gran diferencia. En los países que tienen el amparo constitucional de derechos fundamentales, éste funciona subsidiariamente a las vías ordinarias, por lo que el ciudadano habrá podido obtener previamente tutela del tribunal de base, con la posibilidad de apelar de su decisión ante la Corte de alzada respectiva. Es decir, se trata de dos instancias ante tribunales que le son a ese ciudadano territorial y económicamente accesibles. Luego le queda la vía más lejana de la casación y al final la vía ante el Tribunal Constitucional.

11 Vid. Taruffo, M. La prova dei fatti giuridici. Nozioni generali, Giuffrè, Milán, 1992, p. 273. 
Sin embargo en algunos casos el transcurso de los tiempos procesales puede conspirar contra las posibilidades de una tutela judicial efectiva. En esos casos el legislador deberá prever una tutela más rápida reduciendo el contradictorio o incluso postergándolo para un momento posterior. Nos encontramos frente a dos de las más típicas tutelas de urgencia o provisional ${ }^{12}$ que rigen en el campo procesal civil y procesal administrativo. Cuando se reduce el contradictorio podemos hablar de una tutela de urgencia vía proceso sumario. La posibilidad de postergar el contradictorio para un momento posterior a la dictación de una medida asegurativa se da en el ámbito de una tutela de urgencia de tipo cautelar. Ese proceso de tipo sumario y aquél cautelar si bien no son los únicos sí aparecen como las vías principales de tutela de urgencia de derechos fundamentales o meramente legales del derecho procesal contemporáneo.

\subsection{Tutela de urgencia vía proceso sumario}

Como desde hace años lo ha explicado un sector de la doctrina procesal ${ }^{13}$ el sentido del proceso sumario hay que entenderlo del siguiente modo. En algunos casos, ya sea por la particularidad de las pruebas o por la naturaleza especial de la relación controvertida, es posible pensar que la cognición ordinaria con un contradictorio completo no habría dado resultados diversos de aquellos que con rapidez y economía el actor ha podido obtener a través de la cognición sumaria. Sin embargo, porque este cálculo de probabilidades podría en concreto resultar equivocado los efectos de la providencia dictada en el procedimiento sumario nacen provisorios. De este modo, dichos efectos pueden posteriormente modificarse de conformidad al resultado de una ulterior fase procesal. En esta etapa posterior, generalmente incoada a iniciativa del demandado, el juez puede ser llamado a examinar en contradictorio completo, propio de la cognición ordinaria, aquella misma relación que en un primer momento había sido objeto de una indagación limitada o superficial.

Hay que tener en consideración que en los procesos sumarios la oposición no se refiere a una simple apelación u otro recurso contra el pronunciamiento sino a poner en movimiento un proceso de primer grado de cognición total y exhaustiva. Dicho de otro modo, los pronunciamientos dictados en los procesos sumarios no producen cosa juzgada material sino formal, por lo que la misma relación jurídica sustantiva puede volver a ser ventilada en un proceso posterior con una cognición plena y exhaustiva.

El proceso sumario supone una cognición más rápida de la cuestión debatida pero no permite romper con el principio del contradictorio y el respeto de derecho de defensa de las partes, aunque sea con caracteres mínimos.

${ }^{12}$ Juan Carlos Marín en Chile habla de tutela provisional como género, que incluiría entre otras especies a la tutela de urgencia. Vid. Marín, J. C. Las medidas cautelares en el proceso civil chileno [....], op. cit., pp. 53 a 67.

${ }^{13}$ Remito en este aspecto a Calamandrei, p. Introducción al estudio sistemático de las providencias cautelares, Librería El Foro, Buenos Aires, 1996, pp. 38 y ss. 
No está de más señalar que cuando se habla de un proceso sumario con estas características no se está pensando en el proceso sumario de los artículos 680 y siguientes del CPC. Éste supone una etapa de cognición plena por lo que lo decidido tendrá plenos efectos de cosa juzgada material sin que se pueda volver a discutir sobre lo mismo en otro proceso de más lato conocimiento. Antes que al proceso sumario de los artículos 680 y siguientes de nuestro CPC me refiero al proceso sumario del tipo interdicto posesorio que regulan los artículos 549 y siguientes del mismo cuerpo legal.

\subsection{Tutela de urgencia vía proceso cautelar}

Existen algunas situaciones especiales en las que se podría pensar en una respuesta del órgano jurisdiccional aun más rápida que la que podría obtenerse vía proceso sumario. En este caso podríamos pensar en una tutela de tipo cautelar.

La evolución que ha experimentado la tutela cautelar ha caminado por dos senderos diversos. Desde una primera perspectiva la tutela cautelar ha avanzado desde un fin meramente asegurativo o precautorio a incluir como fines cautelares la conservación de un statu quo y la anticipación de todo o parte de la pretensión deducida en el juicio. ${ }^{14}$ Desde otra perspectiva la tutela cautelar ha reclamado en ocasiones una autonomía estructural en relación a un proceso sobre el mérito o principal.

En relación a la autonomía estructural de la tutela cautelar un sector de la doctrina admite la posibilidad de concebir al proceso cautelar como una vía de tutela urgente y directa de los derechos e intereses de los ciudadanos necesitados de tutela jurisdiccional sin que se limite simplemente a cautelar instrumentalmente un proceso de principal. Hablaríamos entonces de una tutela cautelar autónoma.

Otros autores, sobre todo en Argentina, no hablarían en estos casos de una tutela de tipo cautelar autónoma sino de una de tipo autosatisfactiva. ${ }^{15}$ Reserva esta doctrina la expresión tutela cautelar sólo a aquellas providencias que instrumentalmente tutelan un proceso de carácter principal. ${ }^{16}$ El proceso cautelar -se dice- no podría jamás dar satisfacción inmediata y autónoma a los derechos e intereses de los ciudadanos. En cambio un proceso de tipo autosatisfactivo sí puede hacerlo. Sin embargo, a mi entender, los supuestos por lo que procedería decretar una medida cautelar autónoma o una

${ }^{14}$ Vid. Marín, J.C. Las medidas cautelares en el proceso civil chileno [....], op. cit., p. 93.

${ }^{15} \mathrm{El}$ principal autor trasandino que ha construido una teoría sobre la tutela autosatisfactiva es Jorge W. Peyrano. Para un estudio de su teoría remito a uno de sus últimos trabajos en la materia: "Régimen de las medidas autosatisfactivas. Nuevas propuestas", en Curso de medidas cautelares, Landoni, A. (director), Fundación de Cultura Universitaria, Montevideo, 1999, pp. 23-237. También véase sobre este aspecto De Los Santos, M. "Medida autosatisfactiva y medida cautelar (semejanzas y diferencias entre ambos institutos procesales)”, en medidas cautelares, Greif, J. (coordinador), Rubinzal-Culzuni editores, Buenos Aires, 2002, pp. 353 y ss.

${ }^{16}$ Cfr. Pérez Ragone, A. "Concepto estructural y funcional de la tutela anticipativa”, en Revista de Derecho Procesal Iberoamericana, 2000, pág. 172. 
medida autosatisfactiva son los mismos por lo que las consideraré como expresiones de una misma institución jurídica. ${ }^{17}$

Los presupuestos de la tutela cautelar autónoma son los comunes a toda tutela cautelar: periculum in mora, fumus boni iuris y proporcionalidad. A ellos, eventualmente, se puede agregar la exigencia de una contracautela. Concurriendo tales presupuestos procedería decretar de inmediato una medida cautelar que proteja los derechos e intereses necesitados de amparo aun en la hipótesis inaudita et altera pars. Dicha medida decretada satisface directamente una determinada situación jurídica sustancial del requirente y no cumple una función meramente asegurativa de un proceso principal.

Como se puede ver, ya sea que la tutela cautelar permita asegurar bienes, mantener un statu quo o anticipar la decisión sobre el fondo, sea todo ello realizado en los términos de un proceso principal necesario u ocasional, lo cierto es que la tutela cautelar se muestra cada vez más como una herramienta útil para hacer frente a los excesivos tiempos de la justicia.

Se trata, como es de obvia comprensión, de tutelas esencialmente provisionales. Por ello son relevantes las palabras de advertencia que formula Giuseppe Tarzia. Sostiene el profesor italiano "que sólo la recuperación de la funcionalidad del proceso ordinario podrá reconducir a los procedimientos cautelares al álveo de aquella función subsidiaria e integradora y no sustitutiva de la jurisdicción ordinaria que corresponde en el diseño legislativo, y lo que más cuenta, en un orden de la justicia civil inspirado por la lógica de la garantía y eficiencia, y no en aquella siempre traumática de la emergencia”. ${ }^{18}$

\section{Tutela de urgencia en el proceso civil}

\subsection{Las providencias civiles de urgencia en el Derecho comparado}

La lentitud que aflige a la mayoría de la justicia civil en el mundo actual ${ }^{19}$ ha llevado a muchos ordenamientos jurídicos a prever formas de tutela más rápidas. Italia es un típico caso en que el exagerado retardo en su justicia civil ${ }^{20}$ ha llevado al legislador a prever formas de tutela sumarias.

El actual Código de procedimiento Civil italiano regula en su Libro Cuarto los procedimientos especiales. Dentro de éstos regula en su título I los procedimientos sumarios y dentro de éstos los procedimientos cautelares (Capítulo III), entre los que se encuentran el secuestro, la denuncia de nueva obra y de daño temido, la instrucción preventiva, los interdictos posesorios y las providencias de urgencia.

${ }^{17}$ En un sentido similar véase Picó i Junoy, J. "De las medidas cautelares a las medidas autosatisfactivas: ¿Un avance del Derecho Procesal?, en Justicia 2001, N 2-4, pp. 262 y ss.

18 Tarzia, G. "La tutela cautelar", en Medidas cautelares, Greif, J. (coordinador), Rubinzal-Culzoni editores, Buenos Aires, 2002, p. 496.

${ }^{19}$ Vid. Marín, J. C. Las medidas cautelares en el proceso civil chileno [...], op. cit. pp. 33 a 46.

${ }^{20}$ Vid. últimamente la publicación I tempi della giustizia. Un progetto per la riduzione dei tempi dei processi civile e penali, Paciotti, E. (editora), Il Mulino, Bolonia, 2006, passim. 
En Italia entonces el género en esta materia lo constituyen los procedimientos sumarios que significan una vía de tutela más rápida que el rito ordinario. La tutela de urgencia es una modalidad de tutela sumaria o rápida. El artículo clave a objeto de nuestra investigación es el 700 que señala que "fuera de los casos regulados en las precedentes secciones de este capítulo (669 bis), quien tiene fundado motivo para temer que durante el tiempo necesario para hacer valer su derecho en vía ordinaria, éste se vea amenazado por un perjuicio inminente e irreparable, puede solicitar al juez las providencias de urgencia, que aparezcan, según las circunstancias, más idóneas para asegurar provisoriamente los efectos de la decisión sobre el fondo".

Se trata de una medida cautelar de carácter residual y contenido atípico cuya utilización se consiente donde con urgencia sea necesario evitar que el normal iter del proceso ordinario devenga en un perjuicio irreparable para el afirmado titular del derecho. Es residual o subsidiaria porque no debe reemplazar a lo que se puede obtener mediante específicas medidas cautelares reguladas en el Código de Procedimiento Civil italiano o en otras leyes.

Por otro lado es una tutela instrumental y preventiva. Instrumental porque supone la presencia de un proceso sobre el mérito. Es preventiva porque supone un posterior pronunciamiento del juez sobre el fondo. ${ }^{21}$

Aspecto muy relevante es la consideración de uno de los presupuestos típicos de las medidas cautelares como lo es el periculum in mora. De conformidad con el art. 700 CPC italiano tiene que haber un "perjuicio inminente e irreparable". Como lo hace ver Nicola Picardi ${ }^{22}$ la evolución de la doctrina y jurisprudencia italianas estableció una primera orientación en el sentido que podrían ser tutelados en vía de urgencia sólo los derechos denominados absolutos, como por ejemplo, el derecho al nombre, a la imagen, etcétera. Los derechos de obligación o de crédito no podían ser tutelados por esta vía ya que ellos no pueden ser perjudicados de manera irreparable. Procede respecto a estos últimos derechos siempre una sustitución equivalente en dinero. Dicha orientación luego cambió y los derechos de obligación o de crédito también fueron tutelados por esa vía en la medida que no tuvieran una función exclusivamente patrimonial. Este es el caso del derecho de alimentos. En definitiva el establecimiento de la irreparabilidad ha sido dejado a la prudencial valoración del juez de la causa.

La doctrina procesal chilena ha dado cuenta de cómo funciona la tutela de urgencia en el Derecho Procesal Civil comparado. De especial interés es la experiencia inglesa que describe Juan Carlos Marín ${ }^{23}$ y la francesa descrita por Enrique Paillás, ${ }^{24}$ a las que

${ }^{21}$ Vid. Picardi, N. Appunti di Diritto Processuale Civile.I processi speciali, esecutivi e cautelari, Giuffrè, Milán, 2002, pp. 162 y 163.

${ }^{22}$ Cfr. Picardi, N. Appunti di Diritto Processuale Civile [...], op. cit. p. 163.

${ }^{23}$ Vid. Marín, J. C. "Notas sobre la tutela provisional en el Derecho inglés: Especial referencia a la freezing o mareva injunction", en Revista de Derecho, Universidad Austral de Chile, Vol. XIII, diciembre de 2002; "Referencia a la tutela cautelar en el Derecho inglés", en Revista de Derecho, Universidad Austral de Chile, Vol. XV, Diciembre de 2003.

${ }^{24}$ Vid. Paillás, E. El Recurso de Protección ante el Derecho comparado, Editorial Jurídica de Chile, Santiago, 1997, pp. 13 a 36. En estas páginas se aborda la institución francesa del référé. 
remito. En dichos trabajos se explicita que muchas de las cuestiones que resuelven las Cortes de Apelaciones chilenas vía Recurso de Protección son solucionadas en dichos países por jueces civiles de base que cuentan con apropiados medios procesales. La urgencia ha entrado en la lógica de toda justicia civil moderna.

La tutela de urgencia de tipo cautelar debe poder ser utilizada para obtener un amparo inmediato en la medida que concurran los presupuestos para ello (fundamentalmente fumus boni iuris y periculum in mora), ya sea que se trate de derechos patrimoniales (derecho de propiedad, derechos de crédito, etc.) o bien extrapatrimoniales (derecho al nombre, a la imagen, a la libertad de expresión, etc) ${ }^{25}$

De especial relevancia para dictar una medida de urgencia de este tipo será la existencia de un efectivo periculum in mora. Ello es muy importante para justificar este tipo de medidas provisionales que alteran el normal funcionamiento de la justicia declarativa. Y menciono este aspecto porque la práctica desarrollada por los tribunales superiores de justicia chilenos en materia de Recurso de Protección evidencia que en las disputas entre privados que suelen resolver no hay propiamente un peligro que justifique la decisión de urgencia. Muchos de los asuntos que son resueltos por esta vía corresponden a disputas sobre derechos patrimoniales que perfectamente podrían ser resueltas por un juicio ordinario ya que no se vislumbra un perjuicio inminente la mayoría de las veces derivado del normal desarrollo del iter procesal.

Ahora bien, si el problema es que el proceso civil ordinario chileno funciona muy lentamente, se deben realizar entonces las reformas necesarias tanto orgánicas como procesales para hacerlo más eficiente. Lo que no se debe hacer es reconducir todo nuestro sistema de tutela jurisdiccional de derechos a la provisionalidad y precariedad de la tutela de urgencia ni menos alterar el cuadro de competencias de los tribunales de justicia como ha ocurrido con el Recurso de Protección.

\section{La tutela de urgencia en el proceso administrativo}

Este último tiempo, en el Derecho comparado, la justicia administrativa ha desarrollado una amplia gama de respuestas judiciales urgentes. Dentro de ellas está la tutela cautelar.

${ }^{25}$ Muchos de estos derechos extrapatrimoniales pueden corresponder a los mismos bienes jurídicos expresados por la categoría de los derechos fundamentales. Sigo en esto a un sector de la doctrina que sostiene la clara cercanía entre los bienes jurídicos que subyacen a los derechos fundamentales y parte importante del derecho privado. Una rápida mirada a la historia del derecho privado, hace ver Andrés Jana, muestra que con mucha anticipación al surgimiento de la noción de derechos constitucionales tal como se le conoce hoy en día, se ha dado la protección a bienes jurídicos como los que subyacen a los derechos fundamentales. Destaca así el caso de la integridad física y psíquica de las personas, su nombre, honor e intimidad. Todos esos bienes han recibido protección en el derecho civil desde los tiempos de formación de la tradición jurídica occidental. En dicha tradición el derecho privado ha sido centralmente el derecho de la persona y su autonomía, el que ha fijado el espacio para que los individuos regulen sus relaciones sociales. Cfr. Jana, A. "La eficacia horizontal de los derechos fundamentales", en Los derechos fundamentales, AA.VV., Seminario en Latinoamérica de Teoría Constitucional y Política, Buenos Aires, 2003. pp. 64 y 65. 
Tradicionalmente el contencioso administrativo de carácter revisor o de anulación contaba con la suspensión del acto administrativo ${ }^{26}$ como única medida cautelar capaz de hacer frente al poder de autotutela ejecutiva de la Administración. Sin embargo, la suspensión ya no será una medida útil cuando se deduzcan otras pretensiones contra la Administración del Estado. ${ }^{27}$ Piénsese en aquellos casos en que lo solicitado sea la cesación de una actividad de la Administración o la orden de realizar un acto o una actuación. En todos esos casos la medida cautelar de suspensión ya no será útil.

En Alemania se dio el primer paso para avanzar más allá de la orden de suspensión del acto administrativo. Así, junto a aquélla, se reconoció la medida provisional como medida cautelar que opera en el caso de que la pretensión deducida no exija la anulación de un acto administrativo. En algunos casos la orden provisional asegura la conservación de la posición jurídica del sujeto amenazada por la Administración. En otros casos permite la obtención de una posición jurídica en favor del ciudadano. ${ }^{28}$

En Francia la evolución ha caminado por hacer aplicable al contencioso administrativo la institución del rèfềè o juicio de urgencia originalmente vigente sólo en el ámbito del proceso civil. ${ }^{29}$ Inicialmente orientado hacia la suspensión del acto administrativo hoy en día destaca el rèfềè provision mediante el cual el administrado puede solicitar una condena inmediata de pago contra la Administración. ${ }^{30}$ Esta modalidad del rèfềè se ha utilizado satisfactoriamente en supuestos de daños por intervenciones quirúrgicas en hospitales públicos y daños causados por obras públicas, entre otros casos. ${ }^{31}$

El rèfèrè provision puede ser considerado como una modalidad de medidas cautelares positivas, es decir, aquellas que ordenan provisoriamente cumplir con un dar, un hacer o un no hacer por parte de la Administración. ${ }^{32} \mathrm{Y}$ ese dar, hacer o no hacer puede ser lo mismo que lo solicitado como pretensión principal. Se acepta hoy en día que lo solicitado cautelarmente coincida con lo solicitado en la pretensión principal.

En el caso de Alemania se ha entendido que la tutela cautelar deriva directamente del derecho fundamental a la tutela judicial (art. 19. 4 LFA). De este modo, se ha justificado plenamente que el juez administrativo pueda anticipar en vía cautelar el

\footnotetext{
${ }^{26}$ En el Derecho público chileno se ha entendido que la suspensión de los actos de la Administración del Estado constituye un principio de general aceptación en el ámbito de la Nulidad de Derecho Público. Vid. Soto Kloss, E. Derecho Administrativo. Bases fundamentales, Tomo II. El principio de juridicidad, Editorial Jurídica de Chile, primera edición, Santiago, 1996, pp. 193 y 194.

${ }^{27}$ Cfr. García de Enterría, E. Hacia una nueva Justicia Administrativa, Civitas, segunda edición, Madrid, 1992 , p. 66.

${ }^{28}$ Cfr. González-Varas, S. La jurisdicción contencioso-administrativa en Alemania, Civitas, primera edición, Madrid, 1993, p. 287.

${ }^{29}$ Cfr. García de Enterría, E. Hacia una nueva Justicia Administrativa, op. cit., pp. 96 y ss.

${ }^{30}$ Cfr. ibid, p. 169.

${ }^{31}$ Cfr. Chinchilla, C. La tutela cautelar en la nueva Justicia Administrativa, Civitas, Universidad Complutense de Madrid, 1991, p. 98

${ }^{32}$ Cfr. Bacigalupo, M. La nueva tutela cautelar en el contencioso - administrativo, Marcial Pons, Madrid, 1999, p. 56; Sammartino, p. M. Principios constitucionales del amparo administrativo. El contencioso constitucional administrativo urgente, Lexis Nexos, Abeledo Perrot, Buenos Aires, 2003, p. 338.
} 
resultado del proceso principal en la medida que ese proceso principal pierda su objeto por el transcurso del tiempo. Es decir, se justifica utilizar la tutela anticipativa en todos aquellos casos en que si no se dicta la medida cautelar no es posible dar tutela judicial efectiva al administrado. ${ }^{33}$

La situación más paradigmática que presenta la doctrina ${ }^{34}$ sobre este aspecto es la que se puede dar en algunos supuestos de campañas políticas. Piénsese en la situación en que un municipio deniega el permiso para utilizar una de sus salas para realizar la asamblea de un partido político poco antes de las elecciones políticas. Si el representante del partido político en cuestión reclama ante un tribunal por esa denegación y solicita urgentemente el permiso para realizar su meeting, esa orden ya no cumple una función de aseguramiento. Se trata simplemente de reconocer que la autorización judicial inmediata de esa reunión política es la única vía de otorgar tutela judicial al que la reclama. Es que de esperar la sentencia definitiva, probablemente habrán pasado las elecciones y la tutela ya no servirá al que la reclamó. El paso del tiempo, en este caso, priva de toda utilidad al proceso sobre el fondo.

Pero la lucha por lograr una total efectividad en la tutela judicial reclamada por los administrados no sólo pasa por dar unas connotaciones más modernas a la tutela cautelar. Hoy en día se ha arribado hasta propugnar al contencioso administrativo preventivo como mejor manera de dar tutela a los derechos e intereses legítimos de los administrados. Con el contencioso preventivo no se está frente a una medida cautelar puesto que no se trata de suspender un acto de la Administración ni menos obtener anticipadamente una prestación contra ésta. Se trata de un contencioso administrativo sobre el fondo realizado con anterioridad al pronunciamiento definitivo de un acto administrativo.

Estamos frente a una manifestación de una justicia que consiste en dictar directamente una sentencia que pone fin de forma preventiva al litigio planteado pronunciándose sobre todas las cuestiones de fondo. ${ }^{35}$ De este modo, el contencioso administrativo preventivo se viene a manifestar como una vía judicial que a su vez es la fase final del procedimiento administrativo.

33 Cfr. Bacigalupo, M. La nueva tutela cautelar en el contencioso - administrativo, op. cit., p. 142. Como lo destaca Santiago González-Varas, en este caso la medida cautelar trasciende del rol de garantía o aseguramiento del proceso principal, para satisfacer en el fondo lo reclamado por el administrado. Se trata de aquellos casos en que de esperarse una resolución sobre el mérito se derivarían perjuicios irreparables para el peticionario. Obviamente, esto supone subvertir radicalmente los principios tradicionales de la tutela cautelar, por lo que un sector importante de la doctrina alemana ha negado que en estos casos se trate de una medida cautelar. Cfr. González-Varas, S. La jurisdicción contencioso-administrativa en Alemania, Civitas, primera edición, Madrid, 1993, pp. 289 y ss.

${ }^{34}$ Cfr. González-Varas, S. La jurisdicción contencioso-administrativa en Alemania, op. cit., p 293; Bacigalupo, M. La nueva tutela cautelar en el contencioso-administrativo, op. cit., p. 142.

${ }^{35}$ Cfr. González-Varas, S. "Hacia un modelo contencioso - administrativo preventivo. El ejemplo de la "ejecución" de las sentencias anulatorias de un plan urbanístico", en Revista de Administración Pública, 163, enero/abril, 2004, p. 45. 
Obviamente esta tutela judicial preventiva no puede pretender vigencia en todo tipo de cuestiones administrativas. Sólo podrá tener aplicación en caso de impugnación de actos administrativos. Se acercaría así esta justicia administrativa preventiva al contencioso constitucional desarrollado por algunos tribunales constitucionales, como el francés y el chileno, aunque con diferencias importantes. En efecto, el contencioso preventivo ante el Consejo Constitucional francés y ante el Tribunal Constitucional chileno sólo puede ser iniciado por órganos políticos y, en algunos limitados supuestos, por actores populares. En algunos casos procede además con carácter obligatorio. En cambio, el contencioso preventivo administrativo sigue regido por el principio de oportunidad puesto que a él se arribaría sólo si un ciudadano interesado (afirma ser titular de un derecho subjetivo o interés legítimo) decide activar dicho proceso. Destaca así el carácter subjetivo de este proceso a diferencia del carácter preponderantemente objetivo del primero.

El contencioso preventivo podrá ser de mucha utilidad tratándose de actos administrativos que de dictarse ocasionarían irremediablemente un perjuicio de difícil reparación para los administrados. Y aun suponiendo que respecto a la impugnación represiva de ese acto administrativo procederá una orden de suspensión, el retraso en el pronunciamiento de ésta por el juez administrativo o la hipótesis de no obtenerla hacen aconsejable no exponer al ciudadano a tales riesgos.

Para terminar en este punto, quiero realizar una valoración final sobre las tutelas de urgencia en materia de justicia administrativa. Dicha valoración debe arrancar de la misma advertencia que se formuló cuando se analizó con un carácter general las tutelas de urgencia. Ellas, en materia de proceso Administrativo y siguiendo a Jean-François Gipoulon, "no son ni pueden ser la solución al problema de la lentitud de la justicia administrativa. La solución, evidentemente, no puede encontrarse si no es equilibrada la demanda de Justicia y los medios materiales y humanos que la sociedad esté dispuesta a dedicar a su satisfacción. Y es que existe una duración mínima de los procesos que la rapidez, garantía de la eficacia de la Administración de justicia, no podría reducir sin atentar contra el principio de contradicción, garantía a su vez fundamental para el justiciable y para el juez mismo. [...] Por consiguiente, la Justicia no se consigue con medidas de urgencia ni con la inmediatez en el fallo, sino a través de la duración adecuada del proceso y de la resolución debidamente fundamentada de los asuntos”. ${ }^{36}$

\section{URGENCIA Y SEGURIDAD JURÍDICA EN EL PROCESO CONSTITUCIONAL DE TUTELA DE DERECHOS FUNDAMENTALES}

En materia de tutela jurisdiccional de los derechos fundamentales la doctrina nacional y comparada adopta a lo menos tres tipos de actitudes en relación a la procedencia de medidas de urgencia. La más común en nuestro medio jurídico es la que sostiene

${ }^{36}$ Gipoulon, J. F. "Las medidas cautelares en la justicia administrativa francesa", en Documentación Administrativa, $\mathrm{N}^{\circ} 239$ (julio-septiembre 1994), pp. 144 y 145. 
que tratándose de derechos fundamentales dicha tutela debe darse por medio de un proceso constitucional urgente de tipo cautelar. ${ }^{37} \mathrm{El}$ amparo de derechos fundamentales ante las Cortes de Apelaciones -en Chile básicamente el habeas corpus y el Recurso de Protección- viene a ser prácticamente la única posibilidad eficaz de dar tutela jurisdiccional al titular del derecho fundamental vulnerado.

Otro sector de la doctrina nacional señala que no es posible dar tutela adecuada a los derechos fundamentales mediante un recurso urgente como nuestro Recurso de Protección. ${ }^{38}$

Una tercera posición proviene del Derecho comparado. Se trata de una posición intermedia. Podemos incluir en esta la tesis de Ignacio Díez - Picazo. Sostiene este autor que la tutela jurisdiccional de derechos fundamentales puede otorgarse vía proceso de urgencia, como podría ser un proceso de tipo sumario, pero nada impide que el proceso ordinario permita dar adecuada tutela a dichos derechos. Lo esencial en este último caso será permitir que se dicten dentro de esa vía ordinaria las medidas cautelares que aseguren la efectividad de la eventual sentencia estimatoria. De este modo, los derechos fundamentales pueden pero no deben necesariamente tutelarse vía tutela de urgencia. ${ }^{39}$

La segunda tesis la ha sostenido últimamente en Chile Gastón Gómez. Sobre ella quiero discutir en el apartado siguiente ya que se centra en dos aspectos centrales para esta investigación: la necesidad de oportunidad de la tutela jurisdiccional de los derechos fundamentales versus seguridad jurídica en la configuración jurisprudencial de los derechos fundamentales.

\section{Urgencia vs seguridad jurídica en la tutela jurisdiccional de derechos fundamentales. Construyendo un debate en el Derecho chileno}

Gastón Gómez ha planteado recientemente que los derechos fundamentales que reciben tutela por medio del Recurso de Protección no son meros derechos subjetivos como los que habitualmente tutela la jurisdicción común u ordinaria. Los derechos fundamentales corresponden a derechos públicos subjetivos. Eso significa que estos derechos tienen una dimensión pública. Se trata de posiciones jurídicas que corresponden a todo ciudadano. De este modo, la tutela jurisdiccional de este tipo de derechos no puede tener sólo un alcance o valor individual para quien recurre. "Ello sería lesionar la finalidad pública y racional -es decir, igualitaria y discernible- que subyace a la Constitución”. ${ }^{40}$ Y agrega que "tal vez debemos invertir la manera de pensar el problema y decir: se ampara o

${ }^{37}$ Por todos vid. Cea, J. L. El sistema constitucional de Chile. Síntesis crítica, Facultad de Ciencias Jurídicas y Sociales, Universidad Austral de Chile, Valdivia, 1999, pp. 41 y 42; 162 y 165.

${ }^{38}$ Vid. Gómez, G. Derechos fundamentales y Recurso de Protección, Ediciones Universidad Diego Portales, Facultad de Derecho, Santiago, de Chile, 2005, p. 19 y ss.

${ }^{39}$ Cfr. Díez-Picazo, I. "El artículo 53.2 de la Constitución: interpretación y alternativas de desarrollo", en Tribunal Constitucional, jurisdicción ordinaria y derechos fundamentales, De la Oliva, A. / Díez Picazo, I., Mcgraw-Hill, primera edición, Madrid, 1996, pp. 132 y ss.

${ }^{40}$ Gómez, G. Derechos fundamentales y Recurso de Protección, op. cit. p. 21. 
tutela en el Recurso de Protección a un individuo lesionado en una posición consagrada por un enunciado constitucional que confiere un derecho fundamental". ${ }^{41}$ Todo ello se traduce en que las decisiones judiciales sobre derechos fundamentales no pueden tener una naturaleza cautelar provisional puesto que se desvanece la dimensión pública e institucional de los derechos fundamentales. Por el contrario, a juicio de Gómez, estas decisiones judiciales han de gozar de grados significativos de invariabilidad en el tiempo. Desde luego la sentencia dictada a tales efectos debe producir efectos de cosa juzgada material. De lo contrario es imposible construir una dogmática constitucional.

Agrega el autor que si se trata de tutelar urgentemente derechos fundamentales para ello están las vías ante la jurisdicción común. En el fondo eso es lo que ha estado haciendo el Recurso de Protección: se ha comportado relativamente bien como una vía ordinaria o común más. Por lo tanto, si se trata de tutelar derechos fundamentales se hace necesario -agrega Gómez-crear otro tipo de procedimiento jurisdiccional que permita efectivamente crear una dogmática constitucional de los derechos fundamentales. Dicho procedimiento debería proceder contra todos los poderes públicos, incluido el Poder Judicial. El órgano natural para conocer de un procedimiento de este tipo es el Tribunal Constitucional. ${ }^{42}$

Las violaciones a derechos de las que se ha hecho cargo el Recurso de Protección en estos últimos casi treinta años, a juicio de Gómez, deben tener una respuesta expedita por los tribunales de justicia comunes. Para ello -propone- deberían mejorarse las medidas precautorias o bien crearse una especie de référé francés o acciones de tipo injunctions del Derecho inglés. Y para las cuestiones administrativas, agrega, deberían crearse tribunales administrativos con competencia para conocer de ellas. ${ }^{43}$

Agrega en esta parte Gastón Gómez que el Recurso de Protección fue mal diseñado puesto que al día de hoy no ha logrado clarificar si es un sustituto de la jurisdicción común o es derechamente una acción constitucional para la tutela de derechos fundamentales. ${ }^{44}$

Se puede concluir de lo que expone Gómez que la tutela de derechos fundamentales no puede realizarse vía procesos de urgencia. No expresa, sin embargo, el autor qué tipo de procedimiento debería ser creado por el legislador para que el Tribunal Constitucional otorgue una verdadera tutela a los derechos fundamentales de los ciudadanos.

Eduardo Aldunate propone una visión diferente del significado del Recurso de Protección como procedimiento urgente cautelar. La tesis de Aldunate ${ }^{45}$ sostiene que en la práctica este recurso constitucional no se ha comportado como un procedimiento cautelar sino que resuelve en la mayoría de los casos el fondo del asunto debatido con

\footnotetext{
41 Ibid.

42 Ibid, p. 235.

${ }^{43}$ Cfr. Ibid. p. 57.

${ }^{44}$ Cfr. Ibid, p. 43.
}

${ }^{45}$ Cfr. Aldunate, E. "La protección al acecho: las consecuencias del abandono de las reglas de interpretación constitucional en el ámbito del Recurso de Protección”, en Revista de Derecho, Universidad Católica de Valparaíso, Volumen XX-1999, pp. 239 y ss. 
un carácter definitivo. De este modo -señalaba años atrás el mismo autor-, la judicatura ordinaria termina en muchos casos por formular una norma constitucional secundaria que se incorpora al orden jurídico. ${ }^{46}$ Como es fácil de comprender, poco o nada tiene que ver todo aquello con la tutela cautelar. Agrega que aunque esto no fuera así, es decir, reconociendo que en algunos casos haya podido actuar como un mecanismo cautelar, ${ }^{47}$ especialmente en los conflictos entre particulares, entonces el Recurso de Protección actúa violando dos pilares fundamentales del Estado de Derecho como lo son el debido proceso y el principio de responsabilidad.

La violación del debido proceso, a su juicio, se explica por lo siguiente. En los conflictos entre particulares el asunto debatido en el Recurso de Protección se trata de una acción u omisión de un particular que, supuestamente, ha perturbado, amenazado o privado a otro sujeto del legítimo ejercicio de sus derechos. En otras palabras ello se puede explicar señalando que el ejercicio de la libertad de un particular produce los efectos que pretendo enervar a través del recurso. Y si la Corte de Apelaciones acoge mi pretensión de protección el tribunal dispondrá una medida que se dirigirá contra la libertad del recurrido. Y esa libertad será amagada sin contradictorio, sin término probatorio y, en definitiva, sin un período de discusión que permita una adecuada defensa de las libertades y derechos del recurrido que la Corte de Apelaciones ha calificado de arbitrarias o ilegales. ${ }^{48}$ Ese proceder viola el derecho al debido proceso del recurrido cuyo ejercicio de su libertad ha sido cuestionada.

Se viola asimismo - a juicio de este autor- el principio de responsabilidad puesto que el recurso transgrede la lógica tradicional del Estado de derecho que consiste en atribuir a los ciudadanos, en principio, una libertad ilimitada que sólo encuentra sus límites cuando expresamente los ha previsto el ordenamiento jurídico que en este caso los articula como responsabilidad emergente para el infractor de una disposición. Las Cortes de Apelaciones en el Recurso de Protección, a juicio del profesor de Valparaíso, funcionan contra este principio de responsabilidad ya que se encargan, en muchos casos, de prevenir el mal uso de la libertad restringiéndola. El Recurso de Protección, entonces, en muchos casos funciona en la lógica de un Estado de Policía antes que un Estado de Derecho. ${ }^{49}$

Para hacer compatible el Recurso de Protección con el respeto del debido proceso y el principio de responsabilidad, Aldunate propone una particular comprensión de la función cautelar del recurso. Se trata de que asuma la función que cumple el babeas corpus

${ }^{46}$ Cfr. Aldunate, E. "Interpretación constitucional y decisión política”, en Revista de Derecho, Universidad Católica de Valparaíso, Volumen XV (1993-1994), p. 59.

${ }^{47}$ No voy a discutir en esta sede si el Recurso de Protección tiene o no naturaleza cautelar. Negando la naturaleza cautelar me he pronunciado en varios trabajos anteriores. Por todos véase últimamente mi trabajo "El Recurso de Protección como proceso de urgencia", en Revista Chilena de Derecho, Vol. 31 No 2 , 2004 , pp. 285 a 287.

${ }^{48}$ Vid. Aldunate, E. "La protección al acecho: las consecuencias del abandono de las reglas de interpretación constitucional en el ámbito del Recurso de Protección”, op. cit. p. 239.

${ }^{49}$ Vid. Aldunate, E. ibid, p. 240. 
donde el tribunal no hace "un examen de fondo sobre la vigencia final del derecho amagado, sino sobre la forma en que se produce una perturbación, privación o amenaza del mismo, y la situación en la que debe quedar el titular del mismo para defenderlo". ${ }^{50} \mathrm{Se}$ trata de darle a la Corte de Apelaciones el poder para mantener un statu quo; de decidir -expresa- un "atrás sin golpes" del boxeo, para que los involucrados en una controversia puedan solucionarla luego por los medios jurídicamente idóneos. ${ }^{51}$

De lo señalado por Aldunate parece deducirse que no es necesario realizar los cambios que propone Gastón Gómez. No sería necesario crear procedimientos de urgencia ante los jueces comunes así como tampoco un procedimiento especial que permita construir una dogmática de los derechos fundamentales. La urgencia cautelar la darían las Cortes de Apelaciones con los recursos de protección y la seguridad jurídica se lograría por medio de las decisiones judiciales de los jueces comunes de base con los procedimientos ordinarios.

Comentando estas propuestas, hay que señalar que el Recurso de Protección chileno no nació para dar una tutela a los derechos fundamentales de los ciudadanos en el marco del valor seguridad jurídica. Nació fundamentalmente para dar tutela urgente a un derecho patrimonial como lo es el derecho de propiedad cuya caracterización estaba y sigue estando más o menos bien definida por nuestro Derecho y por la cultura jurídica chilena y comparada. Con el tiempo, y alejándose del fin político por el cual fue inicialmente diseñado, comenzó a ser utilizado para dar tutela a otros derechos fundamentales cuyos contornos no están precisados por el ordenamiento jurídico ni por la cultura jurídica. ${ }^{52}$ $\mathrm{Y}$ desde ese momento la utilización de este instrumento comienza a generar problemas en nuestro sistema jurídico ya que son los jueces, en muchas situaciones, los que configuran particularmente el contenido de esos derechos fundamentales.

El Recuso de Protección, tal como se encuentra regulado al día de hoy, sólo se muestra parcialmente apropiado a la hora de tutelar derechos patrimoniales como el de propiedad. ${ }^{53}$ No resulta propicio, sin embargo, como vía general de tutela de derechos fundamentales.

A mi modo de ver, para que los derechos fundamentales puedan tutelarse correctamente se hace indispensable una doble mediación. En primer lugar se requiere que el legislador especifique o colme el ámbito material de los derechos fundamentales. Esa función dentro de un Estado Constitucional de Derecho debe ser realizada por el legislador democrático y no por los jueces como sucede actualmente con el Recurso de Protección. ${ }^{54}$

${ }^{50}$ Aldunate, E. ibid, p. 238.

51 Vid.

52 Andrés Jana señala que en los derechos fundamentales el núcleo relativo al interés protegido por el derecho es muy difuso, especialmente cuando esos derechos inciden sobre relaciones entre particulares. Cfr. Jana, A. "La eficacia horizontal de los derechos fundamentales", op. cit. p. 66.

53 No voy a cuestionar en esta sede si el derecho de propiedad es un verdadero derecho fundamental, cuestión a la que ya me he referido en otras oportunidades. Vid. Bordalí, A. Temas de Derecho Procesal Constitucional, Editorial Fallos del Mes, Santiago de Chile, 2003, pp. 84 y 85.

${ }^{54}$ Vid. Jana, A. "La eficacia horizontal de los derechos fundamentales", en op. cit. p. 69. 
Un buen ejemplo de lo que estamos hablando es lo que ha sucedido en materia del derecho fundamental a vivir en un medio ambiente libre de contaminación (19 $\mathrm{N}^{\circ} 8$ CPR). Desde los primeros años de vigencia de la Constitución de 1980 eran los jueces de protección quienes definían lo que había que entender por medio ambiente y por contaminación de éste. Después de 1994, fecha de promulgación de la Ley de Bases del Medio Ambiente, comienzan a darse conceptos normativos (legales y reglamentarios) sobre estos temas que son los que en definitiva configuran el derecho fundamental en cuestión. A mi juicio desde 1994 en adelante hay más posibilidades de dar protección jurisdiccional a este derecho fundamental en el marco de un Estado Constitucional de Derecho y con respeto del valor seguridad jurídica.

En segundo lugar se requiere una mediación en el sentido que el legislador entregue a los jueces comunes de base la competencia para conocer de las solicitudes de tutela de los derechos fundamentales. Esa tutela puede realizarse por las vías ordinarias existentes o las ordinarias que predisponga el legislador a tal efecto. Ahora bien, si realmente concurren los presupuestos del fumus boni iuris y periculum in mora deberán crearse instrumentos cautelares específicos o bien un poder cautelar general en manos de los jueces que permitan conservar el derecho, mantener el statu quo o inclusive anticipar la decisión sobre el fondo. Todo ello supone introducir reformas a la Constitución como a determinados cuerpos legales.

Esa modificación constitucional y legal significa suprimir la competencia de las Cortes de Apelaciones para conocer del Recurso de Protección (art. 20 CPR) traspasando esa competencia a los jueces de letras y a los tribunales que conozcan del contenciosoadministrativo, atribuyéndoles específicos instrumentos de tutela de urgencia, cautelar o no cautelar. Esa es la propuesta que a mi modo de ver normaliza de mejor modo el sistema de tutela jurisdiccional de derechos fundamentales en el Derecho chileno. Tiene, claro está, el inconveniente de la irrealidad política que supone volver a modificar la Constitución y, sobre todo, supone la supresión de un instrumento procesal que ha calado profundamente en la cultura jurídica chilena.

Si atendemos al criterio de la realidad política hay posibilidades de cambiar el funcionamiento del Recurso de Protección sin implicar modificaciones constitucionales ni legales. Eso pasaría por asumir una posición cautelar más restringida del Recurso de Protección que lo visualiza sólo como un instrumento capaz de mantener un statu quo. En este caso el Recurso de Protección jamás se pronunciaría sobre cuestiones de fondo sobre el derecho fundamental amagado sino sólo un pronunciamiento formal sobre cómo se ha producido una vulneración del derecho. Se trata del "atrás sin golpes” que propone Aldunate. Como no hay pronunciamiento sobre el fondo si el interesado quiere obtener una respuesta jurisdiccional en ese sentido deberá recurrir a las vías que el ordenamiento jurídico disponga. A falta de otras será hoy en día el procedimiento ordinario del Código de Procedimiento Civil (art. $3^{\circ}$ ).

Esta interpretación si bien no permite solucionar el problema de la alteración de competencias que supone hacer de las Cortes de Apelaciones tribunales de primera instancia y de la Corte Suprema un tribunal de apelación, sí puede permitir solucionar los otros problemas que se han denunciado en este trabajo. No obstante, la seguridad 
jurídica reclama otras medidas. Hará falta siempre una mayor coordinación entre los tribunales de justicia con competencias para tutelar los derechos fundamentales. Sobre este último punto me haré cargo en el apartado siguiente.

\section{Derechos fundamentales y seguridad jurídica}

Cualquiera sea la solución que se adopte según el análisis efectuado precedentemente, es decir, suprimir el Recurso de Protección o bien reinterpretar la institución en el sentido de un mero "atrás sin golpes", hará falta adicionalmente un instrumento que permita construir una dogmática clara sobre los derechos fundamentales. A mi juicio, las decisiones sobre el contenido de los derechos fundamentales deberían ser unificadas bajo la dirección del Tribunal Constitucional. La tarea de unificación de la jurisprudencia en materia de derechos fundamentales debería ser hoy en día tarea del Tribunal Constitucional y no de la Corte Suprema. ${ }^{55}$ Se necesita de este modo crear un proceso ante el Tribunal Constitucional tipo amparo constitucional que es la vía utilizada en países como España para "asegurar el sometimiento de los jueces y los tribunales ordinarios a la jurisprudencia del Tribunal Constitucional". ${ }^{56}$ Hablamos de algo similar a una casación constitucional. ${ }^{57}$

55 En este sentido, esta propuesta coincide parcialmente con lo sostenido con Eduardo Soto Kloss en cuanto a que en materia de amparo de derechos fundamentales se hace indispensable unificar las decisiones de los tribunales de justicia. Plantea este autor que dicha labor le corresponde a la Corte Suprema la que debe figurar como Supremo Tribunal de Justicia de la República y no como un mero tribunal de instancia. Sin embargo, sostengo que hoy en día la unificación jurisprudencial y, por ende, la seguridad jurídica, se garantizan de mejor modo si la unificación jurisprudencial se le encomienda al Tribunal Constitucional y no a la Corte Suprema. En materia de justicia constitucional, el Supremo Tribunal de Justicia de la República debe ser el Tribunal Constitucional. Para la tesis de Eduardo Soto Kloss remito a su libro El Recurso de Protección [...], op. cit. p. 302.

56 Aragón, M. "Problemas del Recurso de Amparo", en La reforma del Recurso de Amparo, Pérez Tremps, p. (coordinador), Instituto de Derecho Público Comparado, Universidad Carlos III de Madrid, Tirant lo Blanch, Valencia, 2004, p. 160.

57 En la doctrina española se discute si el amparo constitucional funciona con una lógica casacional. Manuel Aragón participa de esa posición, ya que ve en el Tribunal Constitucional al máximo intérprete de los derechos fundamentales, con facultades para casar y revisar las sentencias de la jurisdicción ordinaria. Cfr. Aragón, M. "Problemas del Recurso de Amparo", en op. cit. pp. 148 y ss. Otros autores no concuerdan con esta caracterización. Carles Viver i Pi-Sunyer señala que el amparo no está actuando en el Derecho español como un recurso de casación o de revisión universal, con duplicación de actividades judiciales. Sólo funciona parcialmente con ese carácter tratándose del derecho a la tutela judicial efectiva (24.1 Constitución española), pero no respecto de los demás derechos. Cfr. Viver i Pi-Sunyer, C. "Diagnóstico para una reforma", en La reforma al Recurso de Amparo, Pérez Tremps, p. (coordinador), Instituto de Derecho Público Comparado, Universidad Carlos III de Madrid, Tirant lo Blanch, Valencia, 2004, pp. 31 y ss. Francisco Rubio y Llorente señala que el amparo no tiene como razón de ser la fijación de la doctrina constitucional, aunque efectivamente también es instrumento para ello. Su objeto principal es la protección de los derechos fundamentales restableciendo en su ejercicio a aquél que se vio privado de él. Por ello, la lógica de la anulación y la posterior retroacción puede ser útil en algunos casos para dar tutela al derecho amagado pero en otros supuestos no lo será. Cuando se trate de dar tutela a derechos fundamentales sustantivos por regla general el reenvío al juez ordinario no se muestra como una medida adecuada para restablecer al amparado en su derecho. Cfr. 
Se podría idear no una casación por violación de la Constitución que daría lugar a miles de recursos al año y, por tanto, sobrecargaríamos innecesariamente al Tribunal. La propuesta consiste en construir en esta materia un recurso de casación en caso de violación de la doctrina del Tribunal Constitucional; un "recurso de casación para la unificación de la doctrina constitucional”. En este caso el Tribunal Constitucional estaría facultado para anular las sentencias de la judicatura ordinaria (de la Corte Suprema fundamentalmente) que violen su doctrina en materia de derechos fundamentales. Sólo así estaremos en condiciones de construir una verdadera dogmática constitucional de los derechos fundamentales. Y sólo así es posible congeniar las necesidades de urgencia con las de seguridad jurídica en la tutela jurisdiccional de los derechos fundamentales.

\section{BIBLIOGRAFÍA}

Aldunate, E., "Interpretación constitucional y decisión política", en Revista de Derecho, Universidad Católica de Valparaíso, Volumen XV (1993-1994).

Aldunate, E., "La protección al acecho: las consecuencias del abandono de las reglas de interpretación constitucional en el ámbito del Recurso de Protección”, en Revista de Derecho, Universidad Católica de Valparaíso, Volumen XX-1999.

Aragón, M., "Problemas del Recurso de Amparo", en La reforma del Recurso de Amparo, Pérez Tremps, p. (coordinador), Instituto de Derecho Público Comparado, Universidad Carlos III de Madrid, Tirant lo Blanch, Valencia, 2004.

Bacigalupo, M., La nueva tutela cautelar en el contencioso-administrativo, Marcial Pons, Madrid, 1999.

Calamandrei, p. Introducción al estudio sistemático de las providencias cautelares, Librería El Foro, Buenos Aires, 1996.

CEA, J. L., El sistema constitucional de Chile. Sintesis crítica, Facultad de Ciencias Jurídicas y Sociales, Universidad Austral de Chile, Valdivia, 1999.

Chinchilla, C., La tutela cautelar en la nueva Justicia Administrativa, Civitas, Universidad Complutense de Madrid, 1991.

De Los Santos, M., "Medida autosatisfactiva y medida cautelar (semejanzas y diferencias entre ambos institutos procesales)", en medidas cautelares, Greif, J. (coordinador), Rubinzal- Culzuni editores, Buenos Aires, 2002.

DíEz-PicAzo, I., "El artículo 53.2 de la Constitución: interpretación y alternativas de desarrollo", en Tribunal Constitucional, jurisdicción ordinaria y derechos fundamentales, De la Oliva, A./Díez-Picazo, I., Mcgraw-Hill, primera edición, Madrid, 1996.

García de Enterría, E., Hacia una nueva Justicia Administrativa, Civitas, segunda edición, Madrid, 1992.

Gipoulon, J. F., "Las medidas cautelares en la justicia administrativa francesa”, en Documentación Administrativa, $\mathrm{N}^{\circ} 239$ (julio-septiembre 1994).

Rubio Llorente F. “El Recuso de Amparo Constitucional”, en La jurisdicción constitucional en España. La Ley Orgánica del Tribunal Constitucional: 1979-1994, AA. VV., Tribunal Constitucional, Centro de Estudios Constitucionales, Madrid, 1995, p. 166. 
Gómez, G., Derechos fundamentales y Recurso de Protección, Ediciones Universidad Diego Portales, Facultad de Derecho, Santiago, de Chile, 2005.

GonZález-VAras, S., La jurisdicción contencioso-administrativa en Alemania, Civitas, primera edición, Madrid, 1993.

GonZÁlez-VAras, S., "Hacia un modelo contencioso - administrativo preventivo. El ejemplo de la "ejecución" de las sentencias anulatorias de un plan urbanístico", en Revista de Administración Pública, 163, enero/abril, 2004.

JANA, A., "La eficacia horizontal de los derechos fundamentales", en Los derechos fundamentales, AA. VV., Seminario en Latinoamérica de Teoría Constitucional y Política, Buenos Aires, 2003.

MARín, J. C., "Notas sobre la tutela provisional en el Derecho inglés: Especial referencia a la freezing o mareva injunction", en Revista de Derecho, Universidad Austral de Chile, Vol. XIII, diciembre de 2002;

Marín, J. C., "Referencia a la tutela cautelar en el Derecho inglés", en Revista de Derecho, Universidad Austral de Chile, Vol. XV, Diciembre de 2003.

Marín, J. C., Las medidas cautelares en el proceso civil chileno. Doctrina, jurisprudencia y Derecho comparado, Editorial Jurídica de Chile, Santiago, 2004.

Millar, J., "Alcance del control de legalidad. Su evolución a propósito de los actos administrativos requisitorios, durante 1970-1973”, en Revista de Derecho, Universidad Austral de Chile, Vol. XI, Diciembre 2000.

PACIOTTI, E., I tempi della giustizia. Un progetto per la riduzione dei tempi dei processi civili e penali, Il Mulino, Bolonia, 2006.

Paillás, E., El Recurso de Protección ante el Derecho comparado, Editorial Jurídica de Chile, Santiago, 1997.

Pérez Ragone, A., "Concepto estructural y funcional de la tutela anticipativa”, en Revista de Derecho Procesal Iberoamericana, 2000.

Peyrano. J.W., "Régimen de las medidas autosatisfactivas. Nuevas propuestas", en Curso de medidas cautelares, Landoni, A. (director), Fundación de Cultura Universitaria, Montevideo, 1999.

Pfeffer, E., "La acción constitucional de protección y su regulación: situación actual y prospectiva", en Estudios Constitucionales, año 2 n 1, Universidad de Talca, 2004.

Picardi, N., Appunti di Diritto Processuale Civile. I processi speciali, esecutivi e cautelari, Giuffrè, Milán, 2002.

Picó I Junoy, J., "De las medidas cautelares a las medidas autosatisfactivas: ¿Un avance del Derecho Procesal?, en Justicia 2001, nº 2-4.

Rubio Llorente F., "El Recuso de Amparo Constitucional”, en La jurisdicción constitucional en España. La Ley Orgánica del Tribunal Constitucional: 1979-1994, AA. VV., Tribunal Constitucional, Centro de Estudios Constitucionales, Madrid, 1995.

Sammartino, p. M. Principios constitucionales del amparo administrativo. El contencioso constitucional administrativo urgente, Lexis Nexis, Abeledo Perrot, Buenos Aires, 2003.

Soto Kloss, E., "Lo contencioso administrativo y los tribunales ordinarios de justicia", en Revista de Derecho Público, Nos 21/ 22, 1977.

Soto Kloss, E., El Recurso de Protección. Orígenes, doctrina y jurisprudencia, Editorial Jurídica de Chile, Santiago, primera edición, 1982.

Soto Kloss, E., Derecho Administrativo. Bases fundamentales, Tomo II. El principio de juridicidad, Editorial Jurídica de Chile, primera edición, Santiago, 1996.

TARuffo, M., La prova dei fatti giuridici. Nozioni generali, Giuffrè, Milán, 1992.

TARZIA, G., "La tutela cautelar", en Medidas cautelares, Greif, J. (coordinador), Rubinzal-Culzoni editores, Buenos Aires, 2002. 
Viver i Pi-SunYer, C., "Diagnóstico para una reforma", en La reforma al Recurso de Amparo, Pérez Tremps, p. (coordinador), Instituto de Derecho Público Comparado, Universidad Carlos III de Madrid, Tirant lo Blanch, Valencia, 2004.

ZÚÑIGA, F., "Recurso de protección: algunas notas sobre sus antecedentes históricos en el siglo XIX”, en Gaceta Jurídica, no 198, diciembre 1996. 